\title{
MAKING ASSESSMENT OF GROUP WORK FAIRER AND MORE INSIGHTFUL FOR STUDENTS AND TIME-EFFICIENT FOR STAFF WITH THE NEW IPAC SOFTWARE
}

\author{
M.P. Garcia-Souto \\ University College London (UNITED KINGDOM)
}

\begin{abstract}
The use of group work activities within HE has grown significantly. It allows academics to use more relevant projects, and it represents a good learning opportunity for students both in terms of knowledge and personal skills gained. However, assessing the group work by means of a group mark that applies to all students is not very popular because of concerns for example with the fairness of the marks, and the appearance of "free riders". One increasingly popular way of addressing these concerns is via the use of the IPAC methodology, i.e. incorporating a moderating individual value that accounts for the level of contribution of a given student to the group work as seen and rated by her/his peers. This is welcome by students, but very time-consuming for staff and impractical to implement unless aided by a dedicated IPAC software.
\end{abstract}

Therefore, an automatic IPAC tool or software is needed so the IPAC methodology can be implemented, improving mark fairness and student experience. This paper presents some priority requirements for the IPAC tool that were identified from extensive literature reading, own experience and numerous conversations with students and other staff members. The paper also presents a new IPAC tool designed and developed at University College London in view of these priorities, which include extensive customization, quick and personalized feedback to students and staff-time efficiency. This paper and software are useful to any academic/teacher setting and assessing group work.

Keywords: Group work, software, IPAC, peer assessment, assessment, feedback.

\section{INTRODUCTION}

Universities and professional bodies increasingly recognize the educational benefits of students working in group projects [1]. However, both staff and students have concerns about the fairness of the assessment when all the team members get the same mark [2-4]. In particular, this leads to poor student experience and numerous complaints of 'free ridders' or 'passengers' [5]. One increasingly popular way of addressing these concerns is via the use of the IPAC methodology, where IPAC stands for Individual Peer $\underline{\text { Assessment of }}$ Contribution to group work [1,3,5-7]. The general idea of the IPAC methodology is represented in Fig. 1. This method of assessment method provides each student with an individual mark which is based in the group mark, but moderated by the IPAC value that represents the student's level of contribution as perceived and scored by her/his peers. Therefore, each individual benefits from the group performing well, as this increases her/his base mark; but the final individual mark received will also be higher the better the student performs with respect to her/his peers. This is seen as fairer by staff [6], is welcome by the students [4,8,9] Who claim are the best people to judge the contribution [4], tackles associated problems, and encourages student engagement and professional behaviour during group work $[1,5,7]$.

However, the implementation of the IPAC methodology is very staff-time consuming. This includes collection of students' views and assessment scores of their peers, selecting and organizing data corresponding to each student within each group, calculating IPAC values and giving each student their individual mark and feedback, etc. For example, it takes an academic about 3-4 full working days to run the IPAC methodology for an 80-students class, despite some parts are automated and the academic is experienced on the process. In practice, this means that without a software to make this process almost or totally automated and efficient, the IPAC methodology is not always used even if beneficial.

This paper presents the features that a software should have to run the IPAC methodology according to staff and student requirements. It also presents the IPAC software developed at University College London (UCL) and that is currently in use. This software allows academics to implement this type of assessment easily and in very little time. 


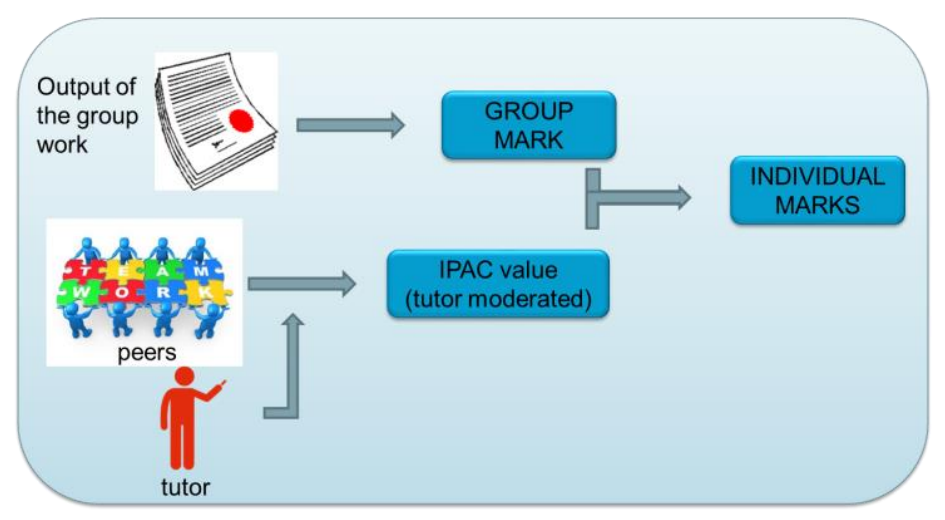

Figure 1. IPAC methodology

\section{METHODOLOGY}

A software is needed to implement the IPAC methodology in a sustainable and efficient way. However, the characteristics and features desired from a software of such nature were unclear. Indications of these desirable features and requirements for one such a software were sought in the literature, as well as via consultation among staff and students at University College London.

A working group of staff was formed at University College London in 2016, namely the IPAC Consortium, to look into the IPAC methodology and identify a solution that could be implemented across the institution. The group included academics from different departments and Faculties, technical staff, and experts in educational practices and assessment. Among other achievements, the group met several times to discuss their current practice and experience in the topic, as well as the problems and challenges of implementing the IPAC methodology. Conversations were also carried out with some students that were also involved with the IPAC Consortium. These students performed 5 focus groups with a range of current university students, mainly to have a better understanding of how students perceived the current method of assessment of group work, and if they would welcome the use of the IPAC methodology. Finally, literature was reviewed where the use of peer assessment of individual contribution to group work was discussed, or where case studies were presented.

Indications were inferred and extracted from these conversations in terms of the features that staff would need and desire from a software designed to facilitate the implementation of the IPAC methodology.

\section{RESULTS}

After these conversations and literature, it was clear that there was a general agreement among practitioners that the IPAC methodology should be used. However, there is not a single way in which academics would implement the IPAC methodology, i.e. how the individual contribution of a student within her/his group is assessed and quantified, and how it is used to moderate the group mark. For instance, there are different formulas that can be used to combine the "group mark" and the "IPAC value" into the "individual marks"; different questions and scales that are used to ascertain the level of contribution; different opinions of the feedback that should be given back to the students from the available information; or even if self-assessment should be included; different moments on time when the peer assessment could take place, etc. The way an academic would assess and obtain the IPAC value is very dependent on the preferences of such academic, and even the circumstances on when it is used, such as the extent of group project, the size of the class, experience of students in peer reviewing others, etc. Therefore, a software designed to run the IPAC methodology must allow staff to have extensive customization.

In terms of practicality, the IPAC software must integrate with the e-learning environment used at the Institution, such that it is easily accessible for the students and it complies with data protection regulations. It should also be easy to install and use by the staff. In terms of the data provided by the software, this should include the raw ratings as well as the calculated values, while keeping these transparent and accessible to the users. Finally, students prefer to receive feedback justifying the marks given by their peers, thought they want these to remain anonymous. 
Based on these preferences, a software designed to run the IPAC methodology should comply with the desired features listed in Table 1. We could not find an existent software that would have all these features, and so a new software was design and developed at UCL addressing each of these requirements. This new IPAC software is presented in section 3.1.

Table 1. List of desired features for a software aimed at running the IPAC methodology

\begin{tabular}{l}
\hline \multicolumn{1}{c}{ Desired features } \\
\hline - Customizable assessment criteria by the staff \\
- Allow among some methodologies to calculate the IPAC values \\
- Provides a range of feedback to the students \\
- Easy to use for students and staff \\
- Complies with data protection regulations \\
- Provides the raw scores \\
\hline \hline
\end{tabular}

\subsection{IPAC software developed at UCL}

A software was designed and developed at UCL to help academics and general staff to implement the IPAC methodology with the group projects that they run. This software was made such that it complies with all the desired features listed in Table 1. Compared to similar current commercial pieces of software, this one presents important benefits. For example, the UCL IPAC software works with Moodle, such that this is the front face used with students; it is easy and quick for individual staff to access it; it allows academics to customize it to their needs and preferences, i.e. choosing the questions, calculation method and feedback they wish to give back to the students, etc.; it presents the data to the staff in a comprehensive and clear way, such that they can understand the dynamics in the groups; and finally, it allows staff to provide individual tutor-led feedback to students very quickly (in a matter of minutes) to even large classes.

The software runs in 3 stages. First the students provide ratings and comment for their peers on their contribution or performance during the group work. Setting this part up might take 20-60 staff minutes depending on the level of customization desired by the user, and if it is the first time that the system is been used - later instances are less time consuming as the setting can be reused. In the second stage, the software analyses the data according to the user preferences and presents it. If the results are approved by the user, these can then be sent back to the students in individual basis in the third stage. The last two stages take about 10 minutes regardless of the class size.

Fig. 2-4 presents some of the characteristics of the software. Fig. 2 presents the student view within Moodle used to collect the students' ratings and comments to their group peers. Staff can customize the number of students, number of questions, rating scales, and text throughout. Fig. 3 presents the settings screen, which includes a selection of calculations and moderations that can be performed, if self-marks are included in the calculations, if staff wants the system to check for and flag profanities in the students' comments, and also the type or types of feedback that the user wants to send to the individual students. Fig. 4 presents two output files where the raw student peer scores and calculated IPAC values are displayed to the staff user in a comprehensive manner. These can be used for a quick identification of disengaged students, high performing students, group dynamics, results of a specific individual or group, etc.

The IPAC software is in use since October 2017 at UCL by a range of staff from several departments, e.g. most of the Engineering departments, Physics, Economics, Arts and Sciences, etc. The software has been used in a range of class sizes, from 10 to 700 students, and it is working well. The fact that the software is available has triggered academics and staff to incorporate the IPAC methodology in assessing significant educational group work activities, which was well received by students. It has also seen staff doing educational research and presenting case studies at conferences describing their experience and insights using the IPAC methodology. One year after the software was deployed, improvements were made according to observations of how staff used the software, and also users' feedback. 


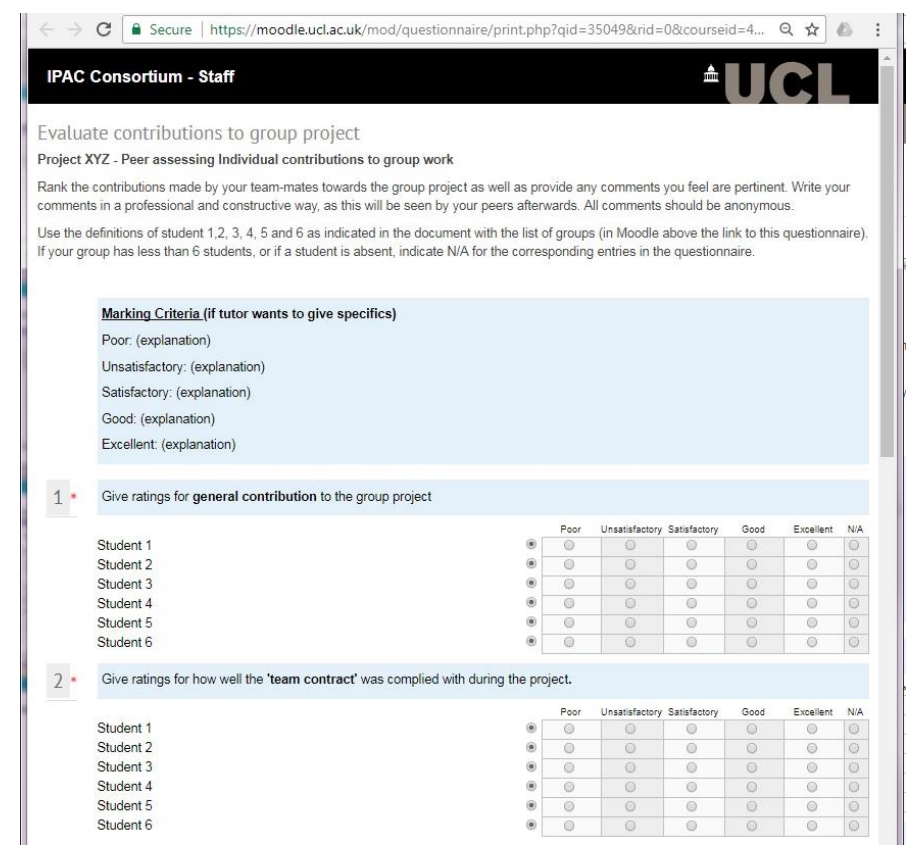

Figure 2. Student view

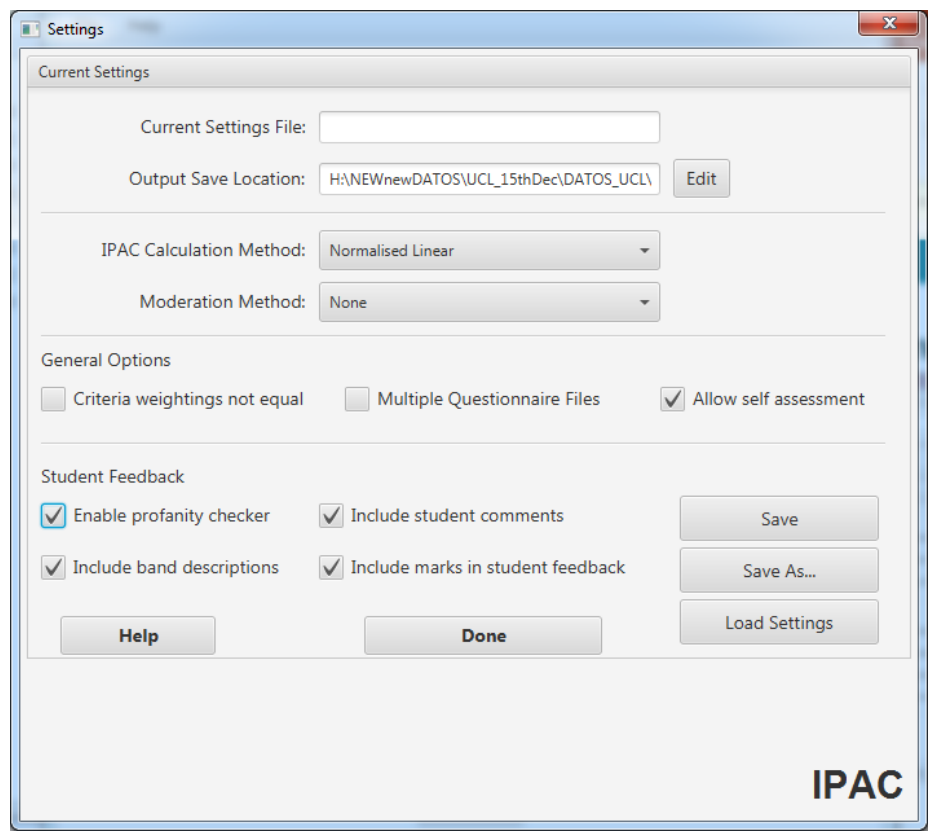

Figure 3. Settings screen of the UCL IPAC software. Copyright (C) 2018 UCL 


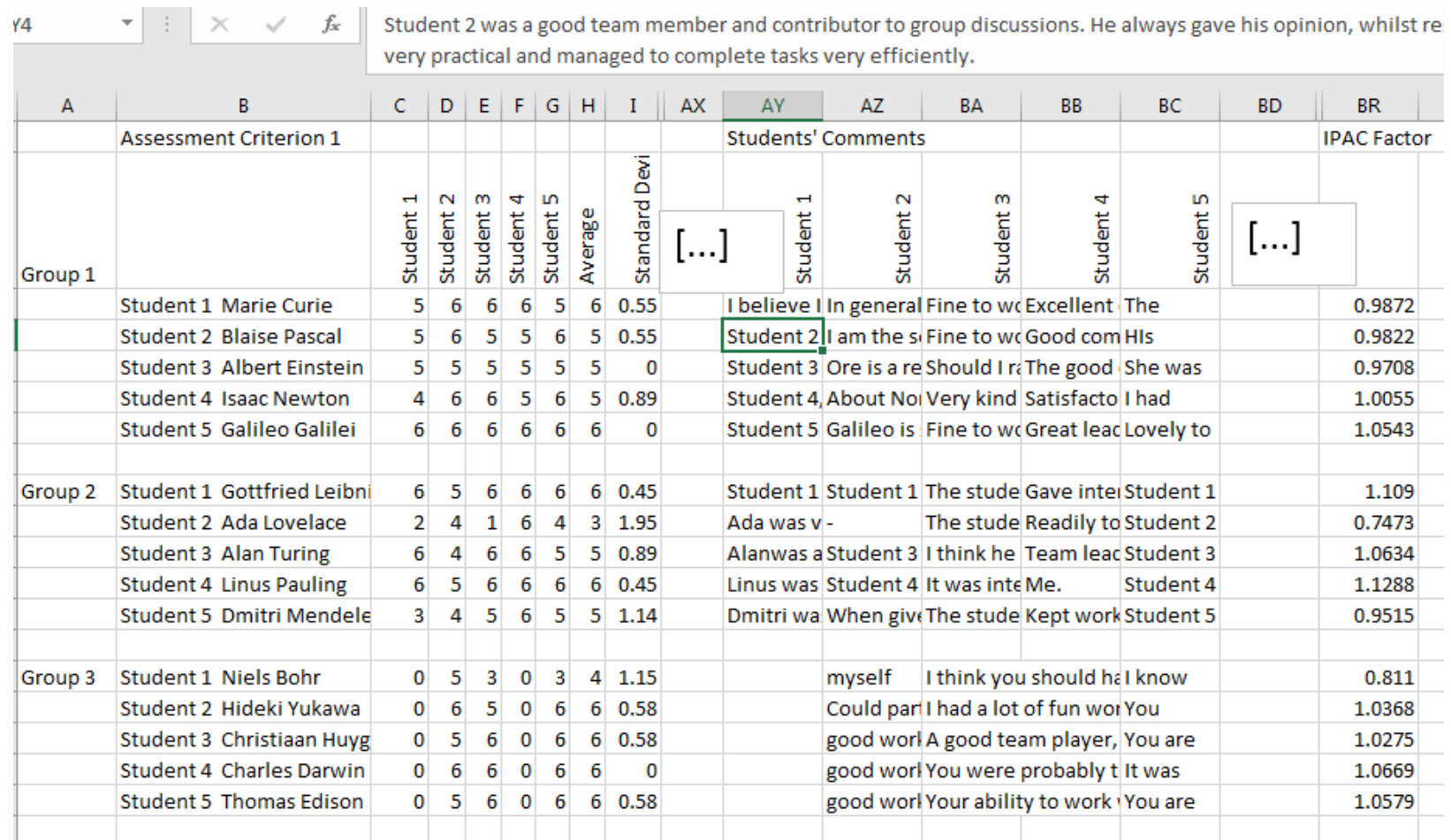

(a)

\begin{tabular}{|c|c|c|c|c|c|c|c|c|c|c|c|}
\hline & K2 & \begin{tabular}{l|l}
$f_{\mathbf{x}}$ & [Aut \\
& Sum \\
& Crite
\end{tabular} & $\begin{array}{l}\text { tomatic tutor fee } \\
\text { nmary of average } \\
\text { eria } 1=6\end{array}$ & $\begin{array}{l}\text { edback specifi } \\
\text { marks receiv }\end{array}$ & $\begin{array}{l}\text { ic for this stuc } \\
\text { ved per assess }\end{array}$ & $\begin{array}{l}\text { dent] and [Peer c } \\
\text { sment criterion. }\end{array}$ & comments for thi & his student] & & & \\
\hline 4 & A & B & c & D & $E$ & $\mathrm{~F}$ & G & H & 1 & $\mathrm{k}$ & $\mathrm{L}$ \\
\hline 1 & Name & Email Address & IPAC Score & C1 Average & C2 Average & C3 Average & C4 Average & C5 Average & C6 Average & Overall Weight: Comments feedback & Flagged Word(s) \\
\hline 2 & Marie Curie & mcarie@ucl.ac.uk & 0.9889 & 5.6 & 5.8 & 5.2 & 5.8 & 5.2 & 5 & 5.43 feedback specific for & \\
\hline 3 & Blaise Pascal & bpascal@ucl.ac.uk & 0.9808 & 5.4 & 5.6 & 5.2 & 5.6 & 5.4 & 5.2 & 5.4 marks received per & \\
\hline 4 & Albert Einstein & aeinstein@ucl.ac.uk & 0.968 & 5 & 5.4 & 5.4 & 5.4 & 5.4 & 5.4 & 5.33 marks received per & \\
\hline 5 & Isaac Newton i & inewton@ucl.ac.uk & 1.0055 & 5.4 & 5.8 & 5.8 & 6 & 4.6 & 5.6 & 5.53 marks received per & \\
\hline 6 & Galileo Galilei & ggalilei@ucl.ac.uk & 1.0568 & 6 & 6 & 5.8 & 6 & 6 & 5 & 5.8 marks received per & \\
\hline 7 & Gottfried Leibni: & gleibniz@ucl.ac.uk & 1.1142 & 5.8 & 5.8 & 6 & 5.6 & 5.6 & 5.6 & 5.73 marks received per & \\
\hline 8 & Ada Lovelace & alovelace@ucl.ac.uk & 0.7351 & 3.4 & 4 & 3.8 & 4 & 3.8 & 4.2 & 3.87 marks received per & \\
\hline 9 & Alan Turing & aturing@ucl.ac.uk & 1.0661 & 5.4 & 5.4 & 5.6 & 5.8 & 5.4 & 5.4 & 5.5 marks received per & \\
\hline 10 & Linus Pauling & Ipauling@ucl.ac.uk & 1.1359 & 5.8 & 5.8 & 5.8 & 5.8 & 6 & 5.8 & 5.83 marks received per & \\
\hline 11 & Dmitri Mendeler & dmendeleev@ucl.ac.uk & 0.9487 & 4.6 & 5.2 & 5.4 & 5.6 & 4 & 4.8 & 4.93 marks received per & \\
\hline 12 & Niels Bohr & nbohr@ucl.ac.uk & 0.8094 & 3.67 & 5.33 & 4.67 & 5 & 3.67 & 4.33 & 4.44 marks received per & \\
\hline 13 & Hideki Yukawa & hyukawa@ucl.ac.uk & 1.0376 & 5.67 & 5.67 & 5 & 6 & 5.67 & 6 & 5.67 marks received per & \\
\hline 14 & Christiaan Huyge $\mathrm{C}$ & єchuygens@ucl.ac.uk & 1.0265 & 5.67 & 5.33 & 6 & 5.33 & 5.67 & 5.67 & 5.61 marks received per & \\
\hline 15 & Charles Darwin & cdarwin@ucl.ac.uk & 1.0685 & 6 & 6 & 5.67 & 6 & 5.33 & 6 & 5.83 marks received per & \\
\hline 16 & Thomas Edison & tedison@ucl.ac.uk & 1.0579 & 5.67 & 5.67 & 6 & 5.67 & 6 & 5.67 & 5.78 marks received per & \\
\hline 17 & Nikola Tesla & ntesla@ucl.ac.uk & 1.0248 & 5 & 5.33 & 6 & 5.33 & 5.67 & 5.33 & 5.44 marks received per & \\
\hline 18 & Max Planck & mplanck@ucl.ac.uk & 1.0632 & 6 & 6 & 6 & 5.33 & 5.33 & 5.33 & 5.67 marks received per & \\
\hline 19 & Ludwig Boltzmar I & I lboltzmann@ucl.ac.uk & 1.0955 & 6 & 6 & 6 & 5.67 & 5.67 & 5.67 & 5.83 marks received per & \\
\hline 20 & Enrico Fermi & efermi@ucl.ac.uk & 0.8165 & 4.67 & 4.67 & 4.33 & 5 & 4.33 & 4.33 & 4.56 marks received per & \\
\hline
\end{tabular}

(b)

Figure 4. Outputs from the UCL IPAC software. Copyright (O) 2017 UCL

\section{CONCLUSIONS}

The use of the IPAC assessment methodology is of interest to any staff or academic that runs and assesses group work, as it encourages students' engagement, reduces "free riders", makes marks fairer and improves student experience. The issue is that implementing this practice without the aid of a purpose made software is very time consuming and therefore impractical. UCL has designed and developed the IPAC software that allows staff to implement and run the IPAC methodology easily, and time-efficiently. Since the software became available, a large growth in the use of this practice has been observed, making a positive and significant change at the institution. It has also facilitated staff to perform educational research and case studies in this type of assessment. 
The developed IPAC software was presented in this paper. The key of its success is that it complies with the features that were identified as desirable by the staff and students, and that were discussed earlier in the paper.

\section{ACKNOWLEDGEMENTS}

Great thanks to all the IPAC Consortium members for their interest, all the discussions and contribution to understanding the IPAC methodology. Also, many thanks to the Vice-provost office for Education and Student Affairs, Medical Physics and Biomedical Engineering Department, Chemical Engineering Department, UCL CC Collab, and UCL Change Makers for their financial support to the IPAC Consortium; this has been key to gain a good understanding of the IPAC methodology. Thanks to the UCL Knowledge and Innovation Fund for supporting the further development and dissemination of the developed software. Finally, thanks to UCLB for their support and assistance.

\section{REFERENCES}

[1] B.R. Oakley, M. Felder, and R. Brent, "Turning student groups into effective teams," Journal of Student Centered Learning, vol. 2, no. 1, pp. 9-34, 2004.

[2] R. Conway, D. Kember, A. Sivan, and M. Wu, "Peer assessment of an individual's contribution to a group project," Assessment \& Evaluation in higher Education, vol. 18, no. 1, 1993.

[3] M.D.P Garcia Souto, T. Kane, G. Hughes, S. Searles-Bryant, A. Gibson, "Moderated peer assessment of individual contribution to group work," UCL Teaching and learning Conference, UCL, London, UK, 19 April 2016.

[4] M.D.P. Garcia Souto, C.N. Striolo, M. Vogel, R. Grammenos, M. Whyndham, G. Hughes, T. Kador, J. Britton, E. Mambetisaeva, M. Richardson, L. Albelda-Gimeno, I. Chester, F. Akinmolayan, M. Pollock, E. Bele, D. Wright, and A. Gibson, "Peer assessing individual contributions in a group project." 50th Society for Research into Higher Education (SRHE) Conference, Celtic Manor, Newport, Wales, UK, 6-8 Dec 2017.

[5] D. Kelley, "Peer Evaluation within a Team Design Project," Journal of Engineering Technology, vol.32, no. 1, pp. 44-50, 2015.

[6] W. Cheng, and M. Warren, "Making a difference: Using peers to assess individual students' contributions to a group project". Teaching in Higher Education, vol. 5, no. 2, pp. 243-255, 2000.

[7] M. Barriopedro Moro, C. Lopez de Subijana, M.A. Gomez Ruano, and A. Rivero Herraiz, "Coevaluation as a strategy to improve working group dynamics: an experience in Sport Sciences," Revista Complutense de Educación, vol. 27, no. 2, pp. 571-584, 2016.

[8] A. Carvalho, "Students' perceptions of fairness in peer assessment: evidence from a problembased learning course," Teaching in Higher Education, vol. 18, no. 5, pp. 491-505, 2013.

[9] N. Elliott, and A. Higgins, "Self and peer assessment - does it make a difference to student group work?" Nurse education in practice, vol. 5, no. 1, pp. 40-8, 2005. 